\title{
Acute ST-segment myocardial infarction-Evolution of treatment strategies
}

\author{
Dennis T. L. Wong ${ }^{1,2}$, Rishi Puri, ${ }^{1,3}$, Peter J. Psaltis ${ }^{1,2}$, Stephen G. Worthley ${ }^{1,3}$, Matthew I. Worthley ${ }^{1,3}$ \\ ${ }^{1}$ Department of Medicine, University of Adelaide, Adelaide, Australia \\ ${ }^{2}$ MonashHeart, Monash Medical Centre, Clayton, Australia \\ ${ }^{3}$ Cardiovascular Research Centre, Royal Adelaide Hospital, Adelaide, Australia \\ Email: drdenniswong@yahoo.com.au
}

Received 29 October 2013; revised 28 November 2013; accepted 6 December 2013

Copyright (c) 2013 Dennis T. L. Wong et al. This is an open access article distributed under the Creative Commons Attribution License, which permits unrestricted use, distribution, and reproduction in any medium, provided the original work is properly cited. In accordance of the Creative Commons Attribution License all Copyrights (C) 2013 are reserved for SCIRP and the owner of the intellectual property Dennis T. L. Wong et al. All Copyright (C) 2013 are guarded by law and by SCIRP as a guardian.

\begin{abstract}
The commonest cause of acute myocardial infarction involves the rupture or erosion of vulnerable atherosclerotic plaques followed by aggregation of platelets and subsequent thrombus formation, leading to partial or complete epicardial coronary arterial occlusion. Over the last 25 years, advancement in therapeutic options for acute myocardial infarction has resulted in substantial improvement in morbidity and mortality. As a result, the absolute risk reduction of in-hospital deaths for patients presenting with STEMI has been on the decline in the last decade. The focus of the treatment for acute myocardial infarction involves achieving epicardial and microvascular patency, prevention of recurrent ischaemic events while balancing the risk of bleeding. This involves antiplatelet and antithrombotic therapies or fibrinolytic agents when timely performance of primary percutaneous coronary intervention is not possible. We review the evolution of treatment strategies for STEMI that has contributed to the improvement in patient outcome.
\end{abstract}

Keywords: Myocardial Infarction; STEMI; PCI; Coronary Artery Intervention

\section{BACKGROUND}

\section{Pathophysiology of Acute Myocardial Infarction}

The commonest cause of acute myocardial infarction involves the rupture or erosion of vulnerable atherosclerotic plaques followed by aggregation of platelets and subsequent thrombus formation, leading to partial or complete epicardial coronary arterial occlusion [1,2]. Microcirculatory perfusion is compromised by this throm- botic process due to reduced coronary artery blood flow through fixed epicardial stenoses, as well as distal embolisation of thrombus. During the early phase of coronary occlusion, the discrepancy between myocardial oxygen supply and demand results in myocardial ischaemia. If ischaemia persists, myocardial injury becomes irreversible, resulting in myocardial necrosis. This typically extends from the subendocardium towards the subepicardium. Reimer and Jennings [3] first described the concept of "wavefront phenomenon of myocardial death". The major determinant of final infarct size, transmural necrosis and microvascular damage is the duration of ischaemia. Previous studies have validated the association between increased duration of ischaemia with worse myocardial perfusion and increased mortality rate in patients treated with fibrinolysis [4] and primary percutaneous coronary intervention (primary-PCI) [5]. Therefore, the cornerstone for management of ST-segment elevation myocardial infarction (STEMI) involves:

1) Rapid restoration of epicardial and microvascular blood flow utilising combination of pharmacological and percutaneous intervention;

2) Prevention of recurrent ischaemic events with antithrombotic and antiplatelet therapies;

3) Reducing effect of myocardial necrosis;

4) Reducing in-hospital and out-of-hospital complications;

5) Preventing future events.

Over the last 25 years, therapeutic options for treatment of patients with myocardial infarction have improved substantially. As a result, the absolute risk reduction of in-hospital deaths for patients presenting with STEMI has been on the decline in the last decade [6]. We review the evolution of treatment strategies for STEMI that has contributed to the improvement in patient outcome. 


\section{REPERFUSION FOR STEMI}

The main goal is prompt reperfusion of myocardial blood flow which has been shown to reduce mortality [7]. The options include pharmacological reperfusion with fibrinolytic agents and primary-PCI. In major centres with primary-PCI capability, primary-PCI has become the standard of care. However, fibrinolysis remains the most viable treatment option in patients presenting to non-PCI capable hospitals whose transport time to a PCI-capable hospital is greater than 120 minutes [8].

\subsection{Fibrinolysis}

A major breakthrough leading to considerable improvement in survival after STEMI was heralded by the introduction of fibrinolysis in the 1990's as a pharmacological reperfusion therapy [9]. The development of fibrinolytic agents has undergone an evolution from non-fibrin specific agents (streptokinase and urokinase) administered via intravenous infusion, to infusions of fibrin-specific agents (tissue plasminogen activator [tPA]), to bolus only fibrin specific agents (rPA, TNK-tPA). The evolution of these fibrinolytic therapies was associated with incremental benefits to outcome. In the seminal GUSTO trial, tPA was first shown to have a mortality advantage over streptokinase [10]. Subsequently, reperfusion with TNKtPA was associated with greater vessel patency than streptokinase, along with less systemic bleeding but similar mortality benefit as tPA [11]. An important advantage conferred by TNK-tPA has been the ease of bolus administration, however, its use has not translated to further reductions in 30-day or late mortality compared to earlier generation fibrinolytics [11]. Nonetheless, its simpler dosage regimen does allow for wider application outside of hospital, more timely administration and fewer treatment errors. Studies have shown that the earlier administration of fibrinolysis is associated with greater benefit in preservation of left ventricular ejection fraction and reduction in mortality [12-14].

\subsection{Failed Fibrinolysis}

Up to $40 \%$ of patients treated with fibrinolysis fail to achieve restored microvascular flow to the infarct territory. This is defined by the persistence of chest pain and less than 50\% reduction in ST-segment elevation at 90 mins after fibrinolysis. The factors associated with failed pharmacological reperfusion include delay to presentation and treatment, infarct location and concomitant therapies [15]. In the case of failed thrombolytic reperfusion, a strong body of evidence supports the role of emergent angiography and rescue PCI rather than re-administration of fibrinolytics [16]. Rescue PCI was shown by Gershlick et al. to be associated with lower rates of death, reinfarction, severe heart failure and stroke 6 months after
STEMI compared to conservative therapy and repeated thrombolysis. The rate of event free survival at 6 months among patients treated with rescues PCI was $84.6 \%$, as compared with $70.1 \%$ among those receiving conservative therapy and $68.7 \%$ among those undergoing repeated thrombolysis (overall $\mathrm{P}=0.004$ ) [16]. Subsequently, a meta-analysis showed that rescue PCI was associated with improved clinical outcomes for STEMI patients after failed fibrinolytic therapy but the benefits is associated with increased risk of stroke and minor bleeding compared to conservative strategy [17]. Other studies such as the ASSENT-4 PCI (Assessment of the Safety and Efficacy of a New Treatment Strategy with Percutaneous Coronary Intervention) have assessed the role of routine emergency PCI after fibrinolysis, (also known as "facilitated PCI") and found that this approach is associated with an increase in the composite of death, heart failure and shock compared to primary-PCI alone (18.6\% vs. $13.4 \%, P=0.005$ ) [18]. Similarly, the use of facilitated PCI after administration of half dose r-PA and abciximab (glycoprotein IIb/IIIa inhibitor) was also found not to improve outcome compared to primary PCI with administration of abciximab in the cath lab in the FINESSE (Facilitated Intervention for Enhanced Reperfusion Speed to Stop Events) trial [19].

\subsection{Primary Percutaneous Coronary Intervention}

Despite the clear benefits of fibrinolytic therapy compared with no reperfusion and its ease of use, there were still issues of both efficacy and safety that limits its use. These issues include:

1) Normalisation of blood flow (as assessed by TIMI flow grade 3 ) occurs in only $50 \%$ - $60 \%$ of patients treated with fibrinolysis $[10,20]$. The clinical benefits of fibrinolytic therapy correlate only with restoration of TIMI grade 3 flow.

2) High incidence $(20 \%-30 \%)$ of early recurrence of ischaemia with $5 \%$ - $15 \%$ [20,21] of frank fibrinolytic coronary reocclusion and reinfarction in 3\% - 5\% [22,23] despite initial apparent successful fibrinolysis.

3) bMajor haemorrhagic complications occurring in $2 \%$ - 3\% of patients with the most serious being intracerebral haemorrhage which occurs in as many as $1 \%$ [24].

4) There is a high proportion (20\% - 30\%) of patients particularly older adults who are not candidates for fibrinolytic therapy because of contraindications such as active internal bleeding, a recent stroke or hypertension [25].

In the early 1990s, it was hypothesised that these problems could be overcome by the use of primary-PCI. Although the implementation of primary-PCI requires more resources and is more difficult to quickly implement than 
fibrinolysis studies have shown that when both methods of reperfusion are available, primary-PCI offer better clinical outcomes than fibrinolysis. In a meta-analysis that reviewed 23 randomised trials consisting of 7739 patients, primary-PCI resulted in lower rates of stroke $(1 \%$ vs. $2 \%, \mathrm{P}=0.004)$, early death $(7 \%$ vs. $9 \%, \mathrm{P}=$ $0.0002)$ and non-fatal reinfarction ( $3 \%$ vs. $7 \%, \mathrm{P}<0.001)$ compared to fibrinolysis [14]. Nonetheless, these benefits of primary-PCI remain firmly dependent on timely implementation. Traditionally, this has been measured by "door-to-balloon time", which represents the interval between presentation of the patient to hospital and the achievement of coronary artery patency by balloon angioplasty. Studies have demonstrated that the incremental gains from primary PCI are lost when door-to-balloon time and door-to-needle time (time from hospital arrival to initiation of fibrinolytic therapy) are greater than 60 min and 114 min respectively [17,26,27]. Notably, relative 1 year mortality rates increase by $7.5 \%$ for every 30 minute delay in reperfusion [28]. Therefore efficient and effective clinical systems that are able to deliver timely and consistent reperfusion are required to preserve the advantage of primary-PCI over fibrinolysis. As reducing door-to-balloon time is crucial, strategies involving the performance of 12-lead ECG triage and emergency department activation of primary-PCI have been proposed. A study including 349 patients showed that such astraegy reduced the median door-to-balloon time from 98 minutes to 56 minutes, compared to conventional strategy [29]. The key to achieving a balance between transfer for primary-PCI and fibrinolysis in hospitals without invasive services remains a challenge. Current guidelines recommend transfer for primary-PCI if the door-to-balloon time is expected to be less than 90 minutes. When this criterion can be satisfied, the DANAMI-2 study showed that transfer for primary-PCI results in lower rates of recurrent myocardial infarction, unplanned revascularisation and stroke compared to onsite fibrinolysis. However a reduction in mortality was not demonstrated [30].

\subsection{In-Lab Strategies during Primary Percutaneous Coronary Intervention}

\subsubsection{Antithrombotic Therapies}

In order to optimally restore myocardial perfusion during primary-PCI, effective antithrombotic therapies are required.Unfractionated heparin (UFH) remains the most common antithrombotic therapy used with an initial intravenous bolus of $70 \mathrm{IU} / \mathrm{kg}$ during primary-PCI. Recent studies have shown that low molecular weight heparin (LMWH) is better than UFH during primary-PCI. An open label ATOLL trial randomly assigned 901 STEMI patients to enoxaparin (intravenous bolus of $0.5 \mathrm{mg} / \mathrm{kg}$ ) or UFH (initial intravenous bolus of 70 - 100 IU without or 50 - 70 IU with glycoprotein IIb/IIIa inhibitor) before primary-PCI [31]. There was no significant reduction in the rate of primary outcome of death, complication of MI, procedure failure or major bleeding with enoxaparin ( $28 \%$ vs. $34 \%$; relative risk 0.83 , 95\% CI 0.68 - 1.01). The secondary end-point of death, recurrent MI or acute coronary syndrome, or urgent revascularisation however occurred significantly less often with enoxaparin (7\% vs. 11\%; relative risk 0.59, 95\% CI 0.38 - 0.91). Furthermore two meta-analyses have concluded that the use of LMWH (generally enoxaparin) compared to UFH leads to lower rates of mortality and major bleeding [32,33].

More recently bivalirudin, a short acting direct thrombin inhibitor, has emerged as alternative and possibly more efficacious antithrombotic therapy during primaryPCI. The HORIZONS AMI trial enrolled 3600 STEMI patients and randomised patients to either bivalirudin (initial bolus of $0.75 \mathrm{mg} / \mathrm{kg}$ followed by an intravenous infusion of $1.75 \mathrm{mg} / \mathrm{kg}$ per hour that was discontinued after PCI) plus provisional glycoprotein IIb/IIIa inhibitor or to UFH plus planned GP IIb/IIIa prior to primary-PCI. Patients treated with bivalirudin had reduced major bleeding ( $8.3 \%$ vs. $4.9 \%, \mathrm{P}<0.001)$. The 30 day cardiac mortality and total mortality were also reduced in the patients treated with bivalirudin $(2.1 \%$ vs. $3.1 \%, \mathrm{P}=$ 0.047) [34].

\subsubsection{Parenteral Antiplatelet Therapies}

Abciximab, a chimeric monoclonal antibody fragment targeting the glycoprotein IIb/IIIa receptor, prevents platelet aggregation by blocking the binding of the GP IIb/IIIa receptor to fibrinogen, thereby inhibiting fibrinogen-platelet bridging. It has been shown to be associated with a reduction in the composite endpoints of death, recurrent myocardial infarction and urgent revascularisation in patients undergoing primary-PCI [35-37]. However in the CADILLAC trial, the clinical benefit of abciximab in stented patients was not confirmed. It was observed that there was no difference in the rate of reinfarction or in left ventricular function at six months [38]. In a meta-analysis, abciximab therapy was associated with significant reductions in mortality at 30 days $(2.4 \%$ vs. $3.4 \%, P=0.047$ with placebo) and six to twelve months $(4.4 \%$ vs. $6.2 \%, \mathrm{P}=0.01)$ and in reinfarction at 30 days $(1.0 \%$ vs. $1.9 \%, \mathrm{P}=0.03)$; in addition there was no increase in bleeding. This analysis provides support for the concept that abciximab is beneficial in reducing acute ischemic events during primary PCI with stenting [39]. The intracoronary delivery of abciximab however has not been proven to be superior to intravenous administration in two recent randomised controlled trials [40,41]. Small molecule glycoprotein IIb/IIIa inhibitors (tirofiban and eptifibatide) have not been extensively studied but mechanistic studies have also suggested im- 
proved vessel patency [42,43].

\subsubsection{Stents}

In patients treated with primary-PCI for STEMI, deployment of stents is now routine. The benefit of drug eluting stent (DES) platforms over bare metal stents (BMS) has been examined. In a meta-analysis that included thirteen clinical trials with 7244 STEMI patients, treatment with DES was associated with decreased target vessel revascularisation and myocardial infarction rates [44]. Furthermore, there was no increase in cardiac death or stent thrombosis occurrence with DES [44].

\subsubsection{Aspiration Thrombectomy}

Another recent development during primary-PCI is aspiration thrombectomy. Thrombus removal using aspiration thrombectomy devices (e.g. EXPORT catheter) has been recognised as a strategy that is associated with better epicardial and myocardial perfusion. This can be explained by less distal embolisation of thrombus ordinarily resulting in microvascular damage. This was first shown by the TAPAS study which randomised 1071 patients to conventional PCI vs. manual thrombus aspiration. Patients treated with thrombus aspiration had lower rates of myocardial blush grade 0 or 1 (17.1 vs. $26.3 \%$, P $<0.001$ ) [45]. In addition to myocardial perfusion measures, a meta-analysis including nine randomised trials with 2417 patients also showed that adjunctive aspiration thrombectomy during primary-PCI is associated with a significant reduction in 30-day mortality [46].

\subsubsection{Reducing Bleeding Complications}

Patients treated with primary-PCI for STEMI are at increased risk of bleeding complications because they are concurrently managed with multiple antithrombotic and antiplatelet therapies. Bleeding complications have been linked with increased morbidity and mortality $[47,48]$. Studies have shown that reduction in bleeding complications may lead to improved longer term clinical outcomes, including mortality [49,50]. A number of pharmacologic and procedural strategies can be employed to reduce the risk of bleeding associated with primary-PCI. The two main strategies that have been associated with reduction in bleeding complications and mortality are bivalirudin and radial artery access. Bivalirudin, a direct thrombin inhibitor, as previously discussed was shown in the HORIZONS AMI study to have reduced major bleeding and mortality in STEMI patients treated with primary-PCI.

\subsubsection{Radial versus Femoral Artery Access}

Important advances have been made in elective PCI with respect to reduced access site bleeding [51] and ultimately post-procedure mortality [52,53], through the advent of radial artery puncture compared to the traditional femoral artery approach. The RIFLE-STEACS (Radial Versus Femoral Randomised Investigation in ST-Elevation Acute Coronary Syndrome) and RIVAL (A Trial of Trans-radial Versus Trans-Femoral Percutaneous Coronary Intervention (PCI) Access Site Approach in Patients With Unstable Angina or Myocardial Infarction Managed With an Invasive Strategy) studies explored the hypothesis that the safety associated with radial artery access may also translate into mortality benefit in STEMI patients. In the latter study, Mehta and colleagues compared the efficacy and bleeding outcomes in patients with STEMI $(n=1958)$ and non STEMI $(n=5063)$ separately in those randomised to radial versus femoral arterial access. They found that radial artery access reduced the primary outcome (death/myocardial infarction/stroke/ non-coronary artery bypass graft related major bleeding) compared with femoral access in all-comers (3.1\% vs. 5.2\%; hazard ratio [HR]:0.6; $\mathrm{P}=0.026$ ) while also reducing the rates of all-cause mortality at 30 days $(1.3 \%$ vs. $3.2 \%$; HR $0.39, \mathrm{P}=0.006$ ) and the composite of death, myocardial infarction and stroke ( $2.7 \%$ vs. $4.6 \%$; HR 0.59; $P=0.031$ ) [54]. Interestingly, this effect on mortality outcome was specific for STEMI patients treated with primary PCI (1.4\% radial vs. 3.1\% femoral; HR: 0.46), as it did not apply to patients in the nonSTEMI cohort ( $3.8 \%$ vs. $3.5 \%, \mathrm{P}=0.49$ ), death $/$ myocardial infarction / stroke (3.4\% vs. $2.7 \%, \mathrm{P}=0.176)$ or all-cause mortality $(1.3 \%$ vs. $0.8 \%, \mathrm{P}=0.082)$ [54]. Similar results were corroborated in the RIFLE-STEACS study, in which 1001 patients were randomised to radial $(\mathrm{n}=500)$ and femoral $(\mathrm{n}=501)$ approach at 4-high volume centres between January 2009 and July 2011. The primary endpoint was the 30-day rate of net adverse clinical events (NACEs) defined as composite of cardiac death, stroke, myocardial infarction, target lesion revascularisation and bleeding. Radial access in patients with STEMI was associated with lower 30-day NACEs compared to femoral access (13.6\% vs. $21 \%)$. In addition, radial access was also associated with significantly lower rates of cardiac mortality (5.2\% vs. 9.2\%), bleeding (7.8\% vs. $12.2 \%, \mathrm{P}=0.026$ ) and shorter hospital stay ( $\mathrm{P}$ $=0.03$ ) [55]. The results of these two studies highlight the safety, efficacy and benefit of radial arterial access during primary-PCI and herald its use as the preferred option in patients with STEMI, for interventional cardiologists who have adequate experience and expertise in radial approach.

\subsection{Oral Pharmacotherapies}

The evolution of our focus in modern treatment of STEMI to invasive management is fundamentally enabled by the developments in antiplatelet and antithrombotic therapies. Our improved understanding that plate- 
lets play a central role in the development of STEMI has led to the use of more effective antiplatelet therapies which has been shown to be improve clinical outcomes. The greatest clinical challenge for the use of these pharmacotherapies is finding the balance between avoiding bleeding events and effective suppression of ischaemic events.

\subsection{Oral Antiplatelet Therapies}

Aspirin has been the mainstay treatment for all patients undergoing either pharmacological or primary-PCI. Therefore, all patients with acute coronary syndromes and without contraindications should receive aspirin 150 - $300 \mathrm{mg}$ [56].

The second class of antiplatelet therapy is thienopyridine antagonist of ADP. It has been shown that patients younger than 75 years treated with fibrinolysis randomised to receive clopidogrel (300 $\mathrm{mg}$ loading dose and 75 mg daily compared with placebo) achieved improved rates of vessel patency 3 - 5 days later with a non-significant reduction in recurrent myocardial infarction (2.5\% vs. $3.6 \%, P=0.08)$ [57]. In addition, among 45,852 patients treated for myocardial infarction, there was a $7 \%$ reduction in hospital mortality following the addition of clopidogrel (75mg a day added to aspirin, without loading dose) compared to placebo [58]. The issue of clopidogrel loading dose was recently evaluated in the CURRENT-OASIS 7 trial which assigned 25,086 patients with ACS (29.2\% STEMI) to either clopidogrel $600 \mathrm{mg}$ loading dose on day 1 followed by $150 \mathrm{mg}$ daily for 6 days and $75 \mathrm{mg}$ thereafter or clopidogrel $300 \mathrm{mg}$ loading dose followed by $75 \mathrm{mg}$ daily [59]. The rate of primary outcome (cardiovascular death, MI, or stroke at 30 days) was not statistically different ( $4.2 \%$ vs. $4.4 \%$, P $=0.3$ ) between the two groups. Major bleeding occurred significantly more often in patients who received higher clopidogrel dose $(2.5 \%$ vs. $2 \%, \mathrm{P}=0.01$ in the overall population and $1.6 \%$ vs. $1.1 \%, \mathrm{P}=0.009$ in the PCI subgroup). However, the higher dose of clopidogrel was associated with a significant reduction in the secondary outcome of definite stent thrombosis among patients who underwent PCI ( $0.7 \%$ vs. $1.3 \%, \mathrm{P}=0.0001)$.

Prasugrel which irreversibly inhibits the $\mathrm{P}_{2} \mathrm{Y}_{12}$ receptor at the same site as clopidogrel was recently compared to clopidogrel in the TRITON-TIMI 38 trial of 13,608 moderate to high risk ACS patients undergoing PCI, including 3534 STEMI patients [60]. In patients with STEMI at 15 month follow up, the primary efficacy endpoint of cardiovascular death, nonfatal MI or nonfatal stroke occurred significantly less often in patients treated with prasugrel (9.9\% vs. $12.4 \%$; HR 0.81; 95\% CI 0.73 $0.9, \mathrm{P}<0.001)$, driven primarily by a significant reduction in nonfatal AMI (7.4\% vs. 9.7\%, $\mathrm{P}<0.001)$. In addition, the rate of definite or probable stent thrombosis was also significantly reduced in the prasugrel group (1.6\% vs. $2.8 \%, \mathrm{P}<0.001)$. However, a subset of patients had increased risk of bleeding, specifically those $>75$ years old, those $<60 \mathrm{~kg}$ in weight and those with a history of prior stroke.

Another antiplatelet agent, ticagrelor which blocks the $\mathrm{P}_{2} \mathrm{Y}_{12}$ receptor reversibly, has a more rapid onset of action than clopidogrel. Its efficacy in the treatment of STEMI has recently been studied in the PLATO trial. At 12 months, the composite primary endpoint (death from vascular causes, MI, or stroke) occurred significantly less often in patients receiving ticagrelor $(9.8 \%$ vs. $11.7 \%$ with clopidogrel, HR 0.84 , 95\% CI 0.77 - 0.92, P < $0.001)$. There was no significant difference in the rates of major bleeding between the two groups (11.6\% and $11.2 \%$, respectively; $\mathrm{P}=0.43$ ), but ticagrelor was associated with a significantly increased risk of major bleeding not related to CABG $(4.5 \%$ vs. $3.8 \%, \mathrm{P}=0.03)$. In addition, the secondary endpoints of the rates of myocardial infarction ( $5.8 \%$ vs. $6.9 \%, \mathrm{P}=0.005)$, death from vascular causes $(4.0 \%$ vs. $5.1 \%, \mathrm{P}=0.001)$, and death from any cause $(4.5 \%$ vs. $5.9 \%$; $\mathrm{P}<0.001)$ were all significantly lower in the ticagrelor group [61].

Taken together, there is compelling evidence for the use of dual therapy with aspirin and complementary antiplatelet agents. The relevant data apply both to the overall management of patients with STEMI and furthermore to the primary PCI setting. Although recent results indicate that prasugrel and ticagrelor may have an advantage over clopidogrel, individual patient criteria relating to the risk of bleeding must be taken into consideration before selecting a regime. Furthermore, the cost and availability of newer agents would also be a consideration.

In summary, the combination of antiplatelet and antithrombotic therapies needs to strike a balance between optimising ischaemic outcomes, while reducing bleeding risk.

1) In general, all patients should receive dual antiplatelet agents (aspirin and Clopidogrel, Prasugrel or Ticagrelol) and one antithrombin agent (unfractionated heparin, enoxaparin, bivalirudin or fondaparinux, but not a combination).

2) In patients with increased risk of bleeding and invasive strategy is planned, use of bivalirudin is supported by strong data [34].

3) In patients with increased risk of bleeding and conservative management is planned, fondaprinux is associated with reduced bleeding and mortality [62].

There is evidence to support the additive benefits of combination antiplatelet agents (aspirin, thienopyridines, and glycoprotein IIb/IIIa inhibition).

4) For patients with elevated troponin levels undergoing PCI, abciximab in addition to clopidogrel and aspirin 
further reduces ischaemic events [63]. This should be commenced in the catheterisation laboratory rather than soon after admission as this has been shown to reduce major bleeding [64].

Further studies are ongoing to help further our understanding in this area and will help refine our approach.

\subsection{Secondary Risk Prevention after Acute Myocardial Infarction}

Following successful reperfusion therapies after acute myocardial infarction, secondary risk prevention including optimal blood pressure control, aggressive lipid lowering therapy, smoking cessation, weight reduction, exercise and participation in a cardiac rehabilitation programme are important for improving outcomes. In a meta-analysis by Clark et al. on secondary risk prevention programmes, clear sustained mortality benefit (risk ratio $0.85,95 \%$ CI $0.77-0.94$ ) was associated with these programmes [65]. Further reductions in ischaemic events are associated with aspirin and clopidogrel. Therefore aspirin should be continued indefinitely and for clopidogrel at least 3 - 12 months. The CURE trial demonstrated that the evidence of benefit from clopidogrel begin to emerge within 24 hours and sustained benefit was observed up to 12 months in patients with acute coronary syndrome [66]. Angiotensin converting enzyme (ACE) inhibitors and angiotensin II receptor blockers has a role in patients with heart failure, anterior infarction or history of previous infarction. Besides blood pressure control, these agents also have a role in reducing left ventricular remodelling [67-69]. In patients with an ejection fraction of less than $40 \%$ without severe renal dysfunction or hyperkalaemia, aldosterone antagonist has mortality benefit and should be considered [70]. The benefit of lipid lowering post acute myocardial infarction is well understood. Patients should be counselled on non-pharmacologic therapy such as exercise, weight reduction and dietary modification. The role of statin therapy, in particular high dose statins, at the time of diagnosis provides substantial reductions in mortality as well as nonfatal ischaemic events [71]. Beta-blockers are also recommended after acute myocardial infarction with beneficial effects on fewer recurrent myocardial infarctions and episodes of ventricular fibrillation. However this benefit has also been associated with increased risk of cardiogenic shock [72]. In patients with severe left ventricular dysfunction post acute myocardial infarction, long acting beta-blockers such as bisoprolol, carverdilol and metoprolol succinate should be considered. In the CAPRICORN trial, carvedilol compared to placebo was associated with lower all cause and cardiovascular mortality when prescribed to patients with left ventricular systolic dysfunction defined by $\mathrm{EF}<40 \%$ [73].

\section{CONCLUSION}

Significant reductions in in-hospital, intermediate and long-term outcomes in patients afflicted with acute myocardial infarction have occurred as a result of the additive benefits of prompt mechanical revascularisation strategies coupled with the administration of up-stream antithrombotic and anti-platelet therapies. Newer anti-platelet agents have impacted upon rates of stent thrombosis, however, at the expense of increased bleeding rates. It is likely that a personalised approach to the chronic management of thrombotic and bleeding risk in patients' postAMI will yield optimal patient outcomes.

\section{REFERENCES}

[1] Falk, E., Shah, P.K. and Fuster, V. (1995) Coronary plaque disruption. Circulation, 92, 657-671. http://dx.doi.org/10.1161/01.CIR.92.3.657

[2] Libby, P. (2001) Current concepts of the pathogenesis of the acute coronary syndromes. Circulation, 104, 365-372. http://dx.doi.org/10.1161/01.CIR.104.3.365

[3] Reimer, K.A., Lowe, J.E., Rasmussen, M.M. and Jennings, R.B. (1977) The wavefront phenomenon of ischemic cell death. 1. Myocardial infarct size vs duration of coronary occlusion in dogs. Circulation, 56, 786-794. http://dx.doi.org/10.1161/01.CIR.56.5.786

[4] Gibson, C.M., Murphy, S.A., Kirtane, A.J., Giugliano, R.P., Cannon, C.P., Antman, E.M., et al. (2004) Association of duration of symptoms at presentation with angiographic and clinical outcomes after fibrinolytic therapy in patients with ST-segment elevation myocardial infarction. Journal of the American College of Cardiology, 44, 980-987. http://dx.doi.org/10.1016/j.jacc.2004.05.059

[5] De Luca, G., Suryapranata, H., Zijlstra, F., Van’t Hof, A.W., Hoorntje, J.C., Gosselink, A.T., et al. (2003) Symptom-onset-to-balloon time and mortality in patients with acute myocardial infarction treated by primary angioplasty. Journal of the American College of Cardiology, 42, 991-997. http://dx.doi.org/10.1016/S0735-1097(03)00919-7

[6] Fox, K.A., Steg, P.G., Eagle, K.A., Goodman, S.G., Anderson Jr., F.A., Granger, C.B., et al. (2007) Decline in rates of death and heart failure in acute coronary syndromes, 1999-2006. The Journal of the American Medical Association, 297, 1892-1900.

http://dx.doi.org/10.1001/jama.297.17.1892

[7] Anderson, J.L., Karagounis, L.A. and Califf, R.M. (1996) Metaanalysis of five reported studies on the relation of early coronary patency grades with mortality and outcomes after acute myocardial infarction. American Journal of Cardiology, 78, 1-8. http://dx.doi.org/10.1016/S0002-9149(96)00217-2

[8] O’Gara, P.T., Kushner, F.G., Ascheim, D.D., Casey Jr., D.E., Chung, M.K., De Lemos, J.A., et al. (2013) ACCF/AHA guideline for the management of ST-elevation myocardial infarction: A report of the American College of Cardiology Foundation/American Heart Asso- 
ciation Task Force on Practice Guidelines. Journal of the American College of Cardiology, 61, e78-e140. http://dx.doi.org/10.1016/j.jacc.2012.11.019

[9] Fibrinolytic Therapy Trialists' (FTT) Collaborative Group (1994) Indications for fibrinolytic therapy in suspected acute myocardial infarction: Collaborative overview of early mortality and major morbidity results from all randomised trials of more than 1000 patients. Lancet, 343, 311-322.

[10] The GUSTO Investigators (1993) An international randomized trial comparing four thrombolytic strategies for acute myocardial infarction. The New England Journal of Medicine, 329, 673-682.

http://dx.doi.org/10.1056/NEJM199309023291001

[11] Van De Werf, F., Adgey, J., Ardissino, D., Armstrong, P.W., Aylward, P., Barbash, G., et al. (1999) Single-bolus tenecteplase compared with front-loaded alteplase in acute myocardial infarction: The ASSENT-2 doubleblind randomised trial. Lancet, 354, 716-722. http://dx.doi.org/10.1016/S0140-6736(99)07403-6

[12] The European Myocardial Infarction Project Group (1993) Prehospital thrombolytic therapy in patients with suspected acute myocardial infarction. The New England Journal of Medicine, 329, 383-389. http://dx.doi.org/10.1056/NEJM199308053290602

[13] Steg, P.G., Bonnefoy, E., Chabaud, S., Lapostolle, F., Dubien, P.Y., Cristofini, P., et al. (2003) Impact of time to treatment on mortality after prehospital fibrinolysis or primary angioplasty: Data from the CAPTIM randomized clinical trial. Circulation, 108, 2851-2856. http://dx.doi.org/10.1161/01.CIR.0000103122.10021.F2

[14] Wallentin, L., Goldstein, P., Armstrong, P.W., Granger, C.B., Adgey, A.A., Arntz, H.R., et al. (2003) Efficacy and safety of tenecteplase in combination with the lowmolecular-weight heparin enoxaparin or unfractionated heparin in the prehospital setting: The Assessment of the Safety and Efficacy of a New Thrombolytic Regimen (ASSENT)-3 PLUS randomized trial in acute myocardial infarction. Circulation, 108, 135-142.

http://dx.doi.org/10.1161/01.CIR.0000081659.72985.A8

[15] Gibson, C.M., Cannon, C.P., Murphy, S.A., Marble, S.J., Barron, H.V. and Braunwald, E. (2002) Relationship of the TIMI myocardial perfusion grades, flow grades, frame count, and percutaneous coronary intervention to long-term outcomes after thrombolytic administration in acute myocardial infarction. Circulation, 105, 1909-1913. http://dx.doi.org/10.1161/01.CIR.0000014683.52177.B5

[16] Gershlick, A.H., Stephens-Lloyd, A., Hughes, S., Abrams, K.R., Stevens, S.E., Uren, N.G., et al. (2005) Rescue angioplasty after failed thrombolytic therapy for acute myocardial infarction. The New England Journal of Medicine, 353, 2758-2768. http://dx.doi.org/10.1056/NEJMoa050849

[17] Wijeysundera, H.C., Vijayaraghavan, R., Nallamothu, B.K., Foody, J.M., Krumholz, H.M., Phillips, C.O., et al. (2007) Rescue angioplasty or repeat fibrinolysis after failed fibrinolytic therapy for ST-segment myocardial infarction: A meta-analysis of randomized trials. Journal of the American College of Cardiology, 49, 422-430. http://dx.doi.org/10.1016/j.jacc.2006.09.033

[18] Keeley, E.C., Boura, J.A. and Grines, C.L. (2003) Primary angioplasty versus intravenous thrombolytic therapy for acute myocardial infarction: A quantitative review of 23 randomised trials. Lancet, 361, 13-20. http://dx.doi.org/10.1016/S0140-6736(03)12113-7

[19] Kindermann, M., Adam, O., Werner, N. and Bohm, M. (2007) Clinical trial updates and hotline sessions presented at the European Society of Cardiology Congress 2007: (FINESSE, CARESS, OASIS 5, PRAGUE-8, OPTIMIST, GRACE, STEEPLE, SCAAR, STRATEGY, DANAMI-2, ExTRACT-TIMI-25, ISAR-REACT 2, ACUITY, ALOFT, 3CPO, PROSPECT, EVEREST, COACH, BENEFIT, MERLIN-TIMI 36, SEARCH-MI, ADVANCE, WENBIT, EUROASPIRE I-III, ARISE, getABI, RIO). Clinical Research in Cardiology, 96, 767786. http://dx.doi.org/10.1007/s00392-0591-z

[20] The GUSTO Angiographic Investigators (1993) The effects of tissue plasminogen activator, streptokinase, or both on coronary-artery patency, ventricular function, and survival after acute myocardial infarction. The New England Journal of Medicine, 329, 1615-1622. http://dx.doi.org/10.1056/NEJM199311253292204

[21] Ohman, E.M., Califf, R.M., Topol, E.J., Candela, R., Abbottsmith, C., Ellis, S., et al. (1990) Consequences of reocclusion after successful reperfusion therapy in acute myocardial infarction. TAMI Study Group. Circulation, 82, 781-791. http://dx.doi.org/10.1161/01.CIR.82.3.781

[22] Gibson, C.M., Karha, J., Murphy, S.A., James, D., Morrow, D.A., Cannon, C.P., et al. (2003) Early and longterm clinical outcomes associated with reinfarction following fibrinolytic administration in the thrombolysis in myocardial infarction trials. Journal of the American College of Cardiology, 42, 7-16. http://dx.doi.org/10.1016/S0735-1097(03)00506-0

[23] Hudson, M.P., Granger, C.B., Topol, E.J., Pieper, K.S., Armstrong, P.W., Barbash, G.I., et al. (2001) Early reinfarction after fibrinolysis: Experience from the global utilization of streptokinase and tissue plasminogen activator (alteplase) for occluded coronary arteries (GUSTO I) and global use of strategies to open occluded coronary arteries (GUSTO III) trials. Circulation, 104, 1229-1235. http://dx.doi.org/10.1161/hc3601.095717

[24] Gore, J.M., Granger, C.B., Simoons, M.L., Sloan, M.A., Weaver, W.D., White, H.D., et al. (1995) Stroke after thrombolysis. Mortality and functional outcomes in the GUSTO-I trial. Global Use of Strategies to Open Occluded Coronary Arteries. Circulation, 92, 2811-2818. http://dx.doi.org/10.1161/01.CIR.92.10.2811

[25] Cannon, C.P., Bahit, M.C., Haugland, J.M., Henry, T.D., Schweiger, M.J., McKendall, G.R., et al. (2002) Underutilization of evidence-based medications in acute ST elevation myocardial infarction: Results of the Thrombolysis in Myocardial Infarction (TIMI) 9 registry. Critical Pathways in Cardiology, 1, 44-52. http://dx.doi.org/10.1097/00132577-200203000-00007

[26] Pinto, D.S., Kirtane, A.J., Nallamothu, B.K., Murphy, S.A., Cohen, D.J., Laham, R.J., et al. (2006) Hospital delays in reperfusion for ST-elevation myocardial infarction: 
Implications when selecting a reperfusion strategy. Circulation, 114, 2019-2025. http://dx.doi.org/10.1161/CIRCULATIONAHA.106.6383 $\underline{53}$

[27] Nallamothu, B.K. and Bates, E.R. (2003) Percutaneous coronary intervention versus fibrinolytic therapy in acute myocardial infarction: Is timing (almost) everything? American Journal of Cardiology, 92, 824-826. http://dx.doi.org/10.1016/S0002-9149(03)00891-9

[28] De Luca, G., Suryapranata, H., Ottervanger, J.P. and Antman, E.M. (2004) Time delay to treatment and mortality in primary angioplasty for acute myocardial infarction: Every minute of delay counts. Circulation, 109, 1223-1225. http://dx.doi.org/10.1161/01.CIR.0000121424.76486.20

[29] Hutchison, A.W., Malaiapan, Y., Jarvie, I., Barger, B., Watkins, E., Braitberg, G., et al. (2009) Prehospital 12-lead ECG to triage ST-elevation myocardial infarction and emergency department activation of the infarct team significantly improves door-to-balloon times: Ambulance Victoria and MonashHEART Acute Myocardial Infarction (MonAMI) 12-lead ECG project. Circulation: Cardiovascular Interventions, 2, 528-534.

http://dx.doi.org/10.1161/CIRCINTERVENTIONS.109.8 $\underline{92372}$

[30] Andersen, H.R., Nielsen, T.T., Rasmussen, K., Thuesen, L., Kelbaek, H., Thayssen, P., et al. (2003) A comparison of coronary angioplasty with fibrinolytic therapy in acute myocardial infarction. The New England Journal of Medicine, 349, 733-742.

http://dx.doi.org/10.1056/NEJMoa025142

[31] Montalescot, G., Zeymer, U., Silvain, J., Boulanger, B., Cohen, M., Goldstein, P., et al. (2011) Intravenous enoxaparin or unfractionated heparin in primary percutaneous coronary intervention for ST-elevation myocardial infarction: The international randomised open-label ATOLL trial. Lancet, 378, 693-703. http://dx.doi.org/10.1016/S0140-6736(11)60876-3

[32] Navarese, E.P., De Luca, G., Castriota, F., Kozinski, M., Gurbel, P.A., Gibson, C.M., et al. (2011) Low-molecularweight heparins vs. unfractionated heparin in the setting of percutaneous coronary intervention for ST-elevation myocardial infarction: A meta-analysis. Journal of Thrombosis and Haemostasis, 9, 1902-1915. http://dx.doi.org/10.1111/j.1538-7836.2011.04445.x

[33] Silvain, J., Beygui, F., Barthelemy, O., Pollack Jr., C., Cohen, M., Zeymer, U., et al. (2012) Efficacy and safety of enoxaparin versus unfractionated heparin during percutaneous coronary intervention: Systematic review and meta-analysis. BMJ, 344, e553.

http://dx.doi.org/10.1136/bmj.e553

[34] Stone, G.W., Witzenbichler, B., Guagliumi, G., Peruga, J.Z., Brodie, B.R., Dudek, D., et al. (2008) Bivalirudin during primary PCI in acute myocardial infarction. The New England Journal of Medicine, 358, 2218-2230. http://dx.doi.org/10.1056/NEJMoa0708191

[35] Montalescot, G., Barragan, P., Wittenberg, O., Ecollan, P., Elhadad, S., Villain, P., et al. (2001) Platelet glycoprotein IIb/IIIa inhibition with coronary stenting for acute myo- cardial infarction. The New England Journal of Medicine, 344, 1895-1903.

http://dx.doi.org/10.1056/NEJM200106213442503

[36] Antoniucci, D., Migliorini, A., Parodi, G., Valenti, R., Rodriguez, A., Hempel, A., Memisha, G. and Santoro, G.M. (2004) Abciximab-supported infarct artery stent implantation for acute myocardial infarction and long-term survival: A prospective, multicenter, randomized trial comparing infarct artery stenting plus abciximab with stenting alone. Circulation, 109, 1704-1706. http://dx.doi.org/10.1161/01.CIR.0000126284.40075.98

[37] Montalescot, G., Antoniucci, D., Kastrati, A., Neumann, F.J., Borentain, M., Migliorini, A., Boutron, C., Collet, J.P. and Vicaut, E. (2007) Abciximab in primary coronary stenting of ST-elevation myocardial infarction: A European meta-analysis on individual patients' data with longterm follow-up. European Heart Journal, 28, 443-449. http://dx.doi.org/10.1093/eurheartj/ehl472

[38] Stone, G.W., Grines, C.L., Cox, D.A., Garcia, E., Tcheng, J.E., Griffin, J.J., Guagliumi, G., Stuckey, T., Turco, M., Carroll, J.D., Rutherford, B.D. and Lansky, A.J. (2002) Comparison of angioplasty with stenting, with or without abciximab, in acute myocardial infarction. New England Journal of Medicine, 346, 957-966. http://dx.doi.org/10.1056/NEJMoa013404

[39] De Luca, G., Suryapranata, H., Stone, G.W., Antoniucci, D., Tcheng, J.E., Neumann, F.J., Van de Werf, F., Antman, E.M. and Topol, E.J. (2005) Abciximab as adjunctive therapy to reperfusion in acute ST-segment elevation myocardial infarction: A meta-analysis of randomized trials. JAMA, 293, 1759-1765. http://dx.doi.org/10.1001/jama.293.14.1759

[40] Thiele, H., Wohrle, J., Neuhaus, P., Brosteanu, O., Sick, P., Prondzinsky, R., et al. (2010) Intracoronary compared with intravenous bolus abciximab application during primary percutaneous coronary intervention: design and rationale of the Abciximab Intracoronary versus intravenously Drug Application in ST-Elevation Myocardial Infarction (AIDA STEMI) trial. American Heart Journal, 159, 547-554. http://dx.doi.org/10.1016/j.ahj.2009.12.038

[41] Gu, Y.L., Kampinga, M.A., Wieringa, W.G., Fokkema, M.L., Nijsten, M.W., Hillege, H.L., Van den Heuvel, F.M., Tan, E.S., Pundziute, G., Van der Werf, R., Guyomi, S.H., Van der Horst, I.C.C., Zijlstra, F. and De Smet, B.J.G.L. (2010) Intracoronary versus intravenous administration of abciximab in patients with ST-segment elevation myocardial infarcttion undergoing primary percutaneous coronary intervention with thrombus aspiration: The comparison of intracoronary versus intravenous abciximab administration during emergency reperfusion of ST-segment elevation myocardial infarction (CICERO) trial. Circulation, 122, 2709-2717. http://dx.doi.org/10.1161/CIRCULATIONAHA.110.0027 41

[42] Valgimigli, M., Percoco, G., Malagutti, P., Campo, G., Ferrari, F., Barbieri, D., Cicchitelli, G., McFadden, E.P., Merlini, F., Ansani, L., Guardigli, G., Bettini, A., Parrinello, G., Boersma, E. and Ferrari, R. (2005) Tirofiban and sirolimus-eluting stent vs abciximab and bare-metal stent for acute myocardial infarction: A randomized trial. JAMA, 
293, 2109-2117. http://dx.doi.org/10.1001/jama.293.17.2109

[43] Gibson, C.M., Kirtane, A.J., Murphy, S.A., Rohrbeck, S., Menon, V., Lins, J., et al. (2006) Early initiation of eptifibatide in the emergency department before primary percutaneous coronary intervention for ST-segment elevation myocardial infarction: Results of the Time to Integrilin Therapy in Acute Myocardial Infarction (TITAN)-TIMI 34 trial. American Heart Journal, 152, 668-675. http://dx.doi.org/10.1016/j.ahj.2006.06.003

[44] Piscione, F., Piccolo, R., Cassese, S., Galasso, G., De Rosa, R., D'Andrea, C. and Chiariello, M. (2010) Effect of drug-eluting stents in patients with acute ST-segment elevation myocardial infarction undergoing percutaneous coronary intervention: A meta-analysis of randomised trials and an adjusted indirect comparison. EuroIntervention, 5, 853-860. http://dx.doi.org/10.4244/EIJV5I7A143

[45] Svilaas, T., Vlaar, P.J., van der Horst, I.C., Diercks, G.F., de Smet, B.J., van den Heuvel, A.F., Anthonio, R.L., Jessurun, G.A., Tan, E.S., Suurmeijer, A.J.H. and Zijlstra, F. (2008) Thrombus aspiration during primary percutaneous coronary intervention. New England Journal of Medicine, 358, 557-567.

http://dx.doi.org/10.1056/NEJMoa0706416

[46] De Luca, G., Dudek, D., Sardella, G., Marino, P., Chevalier, B. and Zijlstra, F. (2008) Adjunctive manual thrombectomy improves myocardial perfusion and mortality in patients undergoing primary percutaneous coronary in- tervention for ST-elevation myocardial infarction: A metaanalysis of randomized trials. European Heart Journal, 29, 3002-3010.

http://dx.doi.org/10.1093/eurheartj/ehn389

[47] Eikelboom, J.W., Mehta, S.R., Anand, S.S., Xie, C., Fox, K.A. and Yusuf, S. (2006) Adverse impact of bleeding on prognosis in patients with acute coronary syndromes. Circulation, 114, 774-782. http://dx.doi.org/10.1161/CIRCULATIONAHA.106.6128 $\underline{12}$

[48] Manoukian, S.V., Feit, F., Mehran, R., Voeltz, M.D., Ebrahimi, R., Hamon, M., Dangas, G.D., Lincoff, A.M., White, H.D., Moses, J.W., King III, S.B., Ohman, E.M. and Stone, G.W. (2007) Impact of major bleeding on 30day mortality and clinical outcomes in patients with acute coronary syndromes: An analysis from the ACUITY Trial. Journal of the American College of Cardiology, 49, 13621368. http://dx.doi.org/10.1016/j.jacc.2007.02.027

[49] Mehran, R., Lansky, A.J., Witzenbichler, B., Guagliumi, G., Peruga, J.Z., Brodie, B.R., Dudek, D., Kornowski, R., Hartmann, F., Gersh, B.J., Pocock, S.J., Wong, S.C., Nikolsky, E., Gambone, L., Vandertie, L., Parise, H., Dangas, G.D. and Stone, G.W. (2009) Bivalirudin in patients undergoing primary angioplasty for acute myocardial infarction (HORIZONS-AMI): 1-year results of a randomised controlled trial. Lancet, 374, 1149-1159. http://dx.doi.org/10.1016/S0140-6736(09)61484-7

[50] Mehta, S.R., Boden, W.E., Eikelboom, J.W., Flather, M., Steg, P.G., Avezum, A., et al. (2008) Antithrombotic therapy with fondaparinux in relation to interventional management strategy in patients with ST- and non-STsegment elevation acute coronary syndromes: an individ- ual patient-level combined analysis of the Fifth and Sixth Organization to Assess Strategies in Ischemic Syndromes (OASIS 5 and 6) randomized trials. Circulation, 118, 2038-2046.

http://dx.doi.org/10.1161/CIRCULATIONAHA.108.7894 $\underline{79}$

[51] Rao, S.V., Ou, F.S., Wang, T.Y., Roe, M.T., Brindis, R., Rumsfeld, J.S. and Peterson, E.D. (2008) Trends in the prevalence and outcomes of radial and femoral approaches to percutaneous coronary intervention: A report from the National cardiovascular data registry. JACC: Cardiovascular Interventions, 1, 379-386.

http://dx.doi.org/10.1016/j.jcin.2008.05.007

[52] Chase, A.J., Fretz, E.B., Warburton, W.P., Klinke, W.P., Carere, R.G., Pi, D., Berry, B. and Hilton, J.D. (2008) Association of the arterial access site at angioplasty with transfusion and mortality: The M.O.R.T.A.L study (Mortality benefit of reduced transfusion after percutaneous coronary intervention via the arm or leg). Heart, 94, 1019-1025. http://dx.doi.org/10.1136/hrt.2007.136390

[53] Valgimigli, M., Saia, F., Guastaroba, P., Menozzi, A., Magnavacchi, P., Santarelli, A., et al. (2012) Transradial versus transfemoral intervention for acute myocardial infarction: A propensity score-adjusted and -matched analysis from the REAL (REgistro regionale AngiopLastiche dell'Emilia-Romagna) multicenter registry. JACC: Cardiovascular Interventions, 5, 23-35. http://dx.doi.org/10.1016/j.jcin.2011.08.018

[54] Mehta, S.R., Jolly, S.S., Cairns, J., Niemela, K., Rao, S.V., Cheema, A.N., et al. (2012) Effects of radial versus femoral artery access in patients with acute coronary syndromes with or without ST-segment elevation. Journal of the American College of Cardiology, 60, 2490-2499. http://dx.doi.org/10.1016/j.jacc.2012.07.050

[55] Romagnoli, E., Biondi-Zoccai, G., Sciahbasi, A., Politi, L., Rigattieri, S., Pendenza, G., et al. (2012) Radial versus femoral randomized investigation in ST-segment elevation acute coronary syndrome: The RIFLE-STEACS (Radial Versus Femoral Randomized Investigation in STElevation Acute Coronary Syndrome) study. Journal of the American College of Cardiology, 60, 2481-2419. http://dx.doi.org/10.1016/j.jacc.2012.06.017

[56] Antiplatelet Trialists' Collaboration (1994) Collaborative overview of randomised trials of antiplatelet therapy-III: Reduction in venous thrombosis and pulmonary embolism by antiplatelet prophylaxis among surgical and medical patients. British Medical Journal, 308, 235-246. http://dx.doi.org/10.1136/bmj.308.6923.235

[57] Sabatine, M.S., Cannon, C.P., Gibson, C.M., Lopez-Sendon, J.L., Montalescot, G., Theroux, P., Claeys, M.J., Cools, F., Hill, K.A., Skene, A.M., McCabe, C.H. and Braunwald, E. (2005) Addition of clopidogrel to aspirin and fibrinolytic therapy for myocardial infarction with ST-segment elevation. New England Journal of Medicine, 352, 1179-1189. http://dx.doi.org/10.1056/NEJMoa050522

[58] Chen, Z.M., Jiang, L.X., Chen, Y.P., Xie, J.X., Pan, H.C., Peto, R., et al. (2005) Addition of clopidogrel to aspirin in 45,852 patients with acute myocardial infarction: Randomised placebo-controlled trial. Lancet, 366, 1607-1621. 
http://dx.doi.org/10.1016/S0140-6736(05)67660-X

[59] Mehta, S.R., Bassand, J.P., Chrolavicius, S., Diaz, R., Eikelboom, J.W., Fox, K.A., et al. (2010) Dose comparisons of clopidogrel and aspirin in acute coronary syndromes. New England Journal of Medicine, 363, 930-942. http://dx.doi.org/10.1056/NEJMoa0909475

[60] Wiviott, S.D., Braunwald, E., McCabe, C.H., Montalescot, G., Ruzyllo, W., Gottlieb, S., Neumann, F.J., Ardissino, D., De Servi, S., Murphy, S.A., Riesmeyer, J., Weerakkody, G., Gibson, C.M. and Antman, E.M. (2007) Prasugrel versus clopidogrel in patients with acute coronary syndromes. New England Journal of Medicine, 357, 2001-2015. http://dx.doi.org/10.1056/NEJMoa0706482

[61] Wallentin, L., Becker, R.C., Budaj, A., Cannon, C.P., Emanuelsson, H., Held, C., et al. (2009) Ticagrelor versus clopidogrel in patients with acute coronary syndromes. New England Journal of Medicine, 361, 1045-1057. http://dx.doi.org/10.1056/NEJMoa0904327

[62] Yusuf, S., Mehta, S.R., Chrolavicius, S., Afzal, R,, Pogue, J., Granger, C.B., et al. (2006) Effects of fondaparinux on mortality and reinfarction in patients with acute ST-segment elevation myocardial infarction: The OASIS-6 randomized trial. JAMA, 295, 1519-1530. http://dx.doi.org/10.1001/jama.295.13.joc60038

[63] Kastrati, A., Mehilli, J., Neumann, F.J., Dotzer, F., Ten Berg, J., Bollwein, H., et al. (2006) Abciximab in patients with acute coronary syndromes undergoing percutaneous coronary intervention after clopidogrel pretreatment: The ISAR-REACT 2 randomized trial. JAMA, 295, 15311518. http://dx.doi.org/10.1001/jama.295.13.joc60034

[64] Stone, G.W., Bertrand, M.E., Moses, J.W., Ohman, E.M., Lincoff, A.M., Ware, J.H., et al. (2007) Routine upstream initiation vs deferred selective use of glycoprotein IIb/IIIa inhibitors in acute coronary syndromes: The ACUITY Timing trial. JAMA, 297, 591-602. http://dx.doi.org/10.1001/jama.297.6.591

[65] Clark, A.M., Hartling, L., Vandermeer, B. and McAlister, F.A. (2005) Meta-analysis: Secondary prevention programs for patients with coronary artery disease. Annals of Internal Medicine, 143, 659-672. http://dx.doi.org/10.7326/0003-4819-143-9-200511010-0 $\underline{0010}$

[66] Yusuf, S., Zhao, F., Mehta, S.R., Chrolavicius, S., Tognoni, G. and Fox, K.K. (2001) Effects of clopidogrel in addition to aspirin in patients with acute coronary syn- dromes without ST-segment elevation. New England Journal of Medicine, 345, 494-502. http://dx.doi.org/10.1056/NEJMoa010746

[67] ISIS-4 (Fourth International Study of Infarct Survival) Collaborative Group (1995) ISIS-4: A randomised factorial trial assessing early oral captopril, oral mononitrate, and intravenous magnesium sulphate in 58,050 patients with suspected acute myocardial infarction. Lancet, 345, 669-685.

http://dx.doi.org/10.1016/S0140-6736(95)90865-X

[68] Pfeffer, M.A., McMurray, J.J., Velazquez, E.J., Rouleau, J.L., Kober, L., Maggioni, A.P., et al. (2003) Valsartan, captopril, or both in myocardial infarction complicated by heart failure, left ventricular dysfunction, or both. New England Journal of Medicine, 349, 1893-1906. http://dx.doi.org/10.1056/NEJMoa032292

[69] The Acute Infarction Ramipril Efficacy (AIRE) Study Investigators (1993) Effect of ramipril on mortality and morbidity of survivors of acute myocardial infarction with clinical evidence of heart failure. Lancet, 342, 821828.

[70] Pitt, B., White, H., Nicolau, J., Martinez, F., Gheorghiade, M., Aschermann, M., et al. (2005) Eplerenone reduces mortality 30 days after randomization following acute myocardial infarction in patients with left ventricular systolic dysfunction and heart failure. Journal of the American College of Cardiology, 46, 425-431. http://dx.doi.org/10.1016/j.jacc.2005.04.038

[71] Cannon, C.P., Braunwald, E., McCabe, C.H., Rader, D.J., Rouleau, J.L., Belder, R., et al. (2004) Intensive versus moderate lipid lowering with statins after acute coronary syndromes. New England Journal of Medicine, 350, 14951504. http://dx.doi.org/10.1056/NEJMoa040583

[72] Chen, Z.M., Pan, H.C., Chen, Y.P., Peto, R., Collins, R., Jiang, L.X., et al. (2005) Early intravenous then oral metoprolol in 45,852 patients with acute myocardial infarction: Randomised placebo-controlled trial. Lancet, 366, 1622-1632. http://dx.doi.org/10.1016/S0140-6736(05)67661-1

[73] Dargie, H.J. (2001) Effect of carvedilol on outcome after myocardial infarction in patients with left-ventricular dysfunction: The CAPRICORN randomised trial. Lancet, 357, 1385-1390.

http://dx.doi.org/10.1016/S0140-6736(00)04560-8 